Old Dominion University

ODU Digital Commons

Philosophy Faculty Publications

Philosophy \& Religious Studies

2014

\title{
Philosophy, Medicine and Health Care - Where We Have Come From and Where We Are Going
}

Michael Loughlin

Robyn Bluhm

Old Dominion University

Jonathan Fuller

Stephen Burtow

Rose E. G. Upshur

See next page for additional authors

Follow this and additional works at: https://digitalcommons.odu.edu/philosophy_fac_pubs

Part of the Bioethics and Medical Ethics Commons, and the Philosophy Commons

\section{Repository Citation}

Loughlin, Michael; Bluhm, Robyn; Fuller, Jonathan; Burtow, Stephen; Upshur, Rose E. G.; Borgerson, Kirstin; Goldenberg, Maya J.; and Kingma, Elselijn, "Philosophy, Medicine and Health Care - Where We Have Come From and Where We Are Going" (2014).

Philosophy Faculty Publications. 40.

https://digitalcommons.odu.edu/philosophy_fac_pubs/40

\section{Original Publication Citation}

Loughlin, M., Bluhm, R., Fuller, J., Buetow, S., Upshur, R. E. G., Borgerson, K., .. Kingma, E. (2014). Philosophy, medicine and health care - where we have come from and where we are going. Journal of Evaluation in Clinical Practice, 20(6), 902-907. doi:10.1111/ jep.12275 
Authors

Michael Loughlin, Robyn Bluhm, Jonathan Fuller, Stephen Burtow, Rose E. G. Upshur, Kirstin Borgerson, Maya J. Goldenberg, and Elselijn Kingma 


\title{
Philosophy, medicine and health care - where we have come from and where we are going
}

\author{
Michael Loughlin PhD, ${ }^{1}$ Robyn Bluhm $\mathrm{PhD},{ }^{2}$ Jonathan Fuller BMSc ${ }^{3}$ Stephen Buetow $\mathrm{PhD},{ }^{4}$ \\ Ross E. G. Upshur MD MA MSc CCFP FRCPC, ${ }^{5}$ Kirstin Borgerson MA PhD, ${ }^{6}$ Maya J. Goldenberg PhD ${ }^{7}$ \\ and Elselijn Kingma Msc (Medicine) MSc (Psychology) MPhil PhD ${ }^{8,9}$
}

\author{
${ }^{1}$ Professor of Applied Philosophy, Department of Interdisciplinary Studies, MMU Cheshire, Crewe, UK \\ ${ }^{2}$ Associate Professor, Department of Philosophy and Religious Studies, Old Dominion University, Norfolk, VA, USA \\ ${ }^{3} \mathrm{PhD}$ student, Faculty of Medicine, University of Toronto, Toronto, ON, Canada \\ ${ }^{4}$ Associate Professor, Department of General Practice, University of Auckland, Auckland, New Zealand \\ ${ }^{5}$ Director, Department of Family and Community Medicine, University of Toronto Joint Centre for Bioethics, Toronto, ON, Canada \\ ${ }^{6}$ Assistant Professor, Department of Philosophy, Dalhousie University, Halifax, NS, Canada \\ ${ }^{7}$ Assistant Professor, Department of Philosophy, University of Guelph, Guelph, Ontario, Canada \\ ${ }^{8}$ Senior Lecturer, Department of Philosophy, University of Southampton, Southampton, UK \\ ${ }^{9}$ Socrates Professor in Philosophy and Technology, Technical University, Eindhoven, The Netherlands
}

\begin{abstract}
Keywords
causality, diagnosis, epistemology, ethics,

evidence-based medicine, experience,

explanation, healthcare, humanity, medicine,

metaphysics, ontology, philosophy, practical

reasoning, progress, science, value, virtue
\end{abstract}

\author{
Correspondence \\ Professor Michael Loughlin \\ Department of Interdisciplinary Studies \\ MMU Cheshire \\ Crewe CW1 5DU \\ UK \\ E-mail: m.loughlin@mmu.ac.uk
}

Accepted for publication: 11 September 2014

doi:10.1111/jep.12275 problems, about the nature of reasoning, science, knowledge and practice, and the relationships between epistemology and ethics, morals and politics [1,5-7].

Applied philosophy has moved a long way from the simplistic application of ethical theories to artificially constructed 'dilemmas', to become a rigorous engagement with questions of medical epistemology, metaphysics, and moral and practical reasoning. The Journal of Evaluation in Clinical Practice (JECP) has played no small part in these developments. From its inception, it has consistently raised questions of an underlying, conceptual nature that all manner of influential commentators either ignored or openly dismissed in pronouncing on how to improve the organization of health services, the ethics of practitioners, the reasoning of clinicians and a host of other issues central to the delivery of health care. 
Those influential authors insisted that there were no significant philosophical or methodological problems with importing concepts from the worlds of commerce and 'management science' into health systems [8-11]. From their perspective, the only really interesting and practically relevant questions concerned how to 'advance' this project in the context of such 'change resistant' environments as the British National Health Service [11]. However, the JECP gave voice to those who questioned the meaningfulness and value of applying concepts such as 'audit' and 'organisational quality' (as derived from business and management theories) to complex health systems and practices [12-15]. In doing so, it fulfilled the proper goal of an academic publication, in resisting what we have previously called 'moderate antiintellectualism' [1]: the view that the practical mind is properly employed in considering thoughtfully questions about 'how to' apply currently fashionable or pervasive ideas and approaches, but not in considering questions about why - or whether - one should wish to adopt these approaches, or in subjecting their underlying ideas and assumptions to rigorous critical scrutiny. We regard the rejection of this view as both definitive of a philosophical outlook and - in accord with John Stuart Mill [16] and George Bernard Shaw [17], respectively - as a necessary precondition for both freedom and progress $[1,5]$.

Similarly, even as the authors of policy documents and 'practical ethics' texts have proceeded as though there were no unresolved questions worth mentioning about 'ethics and values' in health care, or as though the resolution of such questions was a straightforward, empirical matter [18-20], contributors to the JECP have exposed a lack of consensus beyond the platitudinous on some of the most pressing questions about the nature and value of health and health care $[4,6]$. These questions include the role of value judgements in clinical diagnosis $[21,22]$, the role of virtue in medical training and practice $[5,6]$, and the role of normative thinking in the definition of health and illness $[23,24]$. The implication, again, is that we need to do more rigorous philosophical thinking, not less, if we are to have anything to say that is at once substantive (going beyond platitudes) and defensible (justifiable in principle to other reasonable people). More thought is required, if we are even to understand the nature of our disagreements, let alone find realistic ways to resolve them [6].

But by far the most significant contribution of the JECP has been to the debate about evidence-based medicine (EBM). Again, resisting from the outset the temptation to treat underlying questions - about the nature of scientific evidence and its relationship with other 'warrants' for clinical decision making - as either settled already or a distraction from the truly 'practical' project of making all practice 'evidence-based', the journal initiated a genuinely critical debate that has transformed our understanding of the relationship between evidence, reasoning and practice. From its early expressions of concern about the limitations of probabilistic reasoning [25] and the rhetorical abuses of the term 'evidence' by leading figures in the EBM movement [26], the journal soon became a major forum for exploring the multiplicity of questions raised by EBM, questions as diverse as: the nature and dimensions of evidence, the epistemology and ontology of causality [27-29]; the relationship between knowledge production and economic and political factors (and the sceptical questions these relationships raise concerning the 'base' research evidence provides for sound practice) [30-32]; the role of context-specific knowledge in clini- cal reasoning $[21,25,33]$; the logic of probabilistic and scientific reasoning [34-38]; the relationship between factual and evaluative reasoning [22-24]; and the need to understand the personal and experiential features of the clinical encounter from the perspectives of both the practitioner and the patient [7,21,39-45]. To do justice to all of these issues, the journal set up a series of special 'EBM thematic' editions [30,40,46-51]. The repeated identification, in editorials of the 'EBM thematics' over several years, of factors EBM's account of sound clinical practice failed to address, logically invited the establishment of a vehicle to address these factors directly. Since 2010, the annual philosophy of medicine thematic issues [1,5-7] have been central to this intellectual undertaking, and to asserting the autonomy of the philosophy of medicine as an academic field worthy of serious pursuit.

These Philosophy Thematic editions have substantially advanced the debate on all of the above issues, developing arguments about virtue epistemology, person-centred care and more broadly extending the ways in which philosophical enquiry can make a substantive contribution to resolving issues of concern in clinical practice. While by no means a full representation of the range of ideas and arguments covered in the thematic editions to date, the articles selected for publication in this philosophy section of the commemorative twentieth anniversary edition of the journal represent some of the key movements in the central debates that have dominated our pages [52-69].

\section{After EBM: explanation, diagnosis, causality and decision making}

We open the section with a series of articles that appraise the current state of EBM, its limitations and prospects for its future development, beginning with a paper that very much vindicates the concerns raised in earlier editions of the JECP [30-32] about the role of political and economic factors in shaping the research agenda [52]. Susanna Every-Palmer and Jeremy Howick argue that the aims of EBM have been undermined by (mostly industryfunded) researchers, who have engaged in selective publication and the deliberate manipulation of research methods. In order to save EBM from the worst aspects of this problem, the authors offer a provocative suggestion: adjust the ranking of industry-funded research to reflect greater scepticism about the trustworthiness of its results. This proposal would be a quick fix for the immediate problem, but should also generate careful reflection on just how far we are from a state of ideal clinical research.

Alexander Mebius wants to move criticism of EBM away from the typical focus on the methodological limits of randomized trials and the hierarchy of evidence [53]. He follows Tonelli [21] and others in arguing for a plurality of methods utilized for corroborating medical claims, suggesting that the strength of the evidential warrant lies in the evidence itself, rather than the methodology used to garner that evidence.

Benjamin Chin-Yee addresses the importance of the underdetermination of theory by evidence (the Duhem-Quine thesis) for the philosophy of medicine [54]. This is an important set of arguments from the philosophy of science that, aside from a paper by Sehon and Stanley [70], has not engendered much attention in the EBM debate. Chin-Yee provides a careful exposition of the thesis and then skilfully shows its application with respect to the tensions between explanations by clinical trials and physio- 
logical mechanisms. Using the example of the chemotherapeutic agent imatinib, Chin-Yee shows how the hierarchy of evidence as articulated by EBM exacerbates the underdetermination of theory by evidence and proposes a pluralistic epistemology as a partial solution to this problem.

The nature and value of explanatory diagnoses and explanatory pluralism are also key preoccupations of the paper by Michael Cournoyea and Ashley Kennedy [55]. These authors propose a methodology for investigating medically unexplained physical symptoms (MUPS). Currently, MUPS are diagnosed via nonexplanatory labels. Yet even when mechanistic explanations remain out of reach, Cournoyea and Kennedy argue that explanatory diagnoses should be pursued. Such diagnoses are preferable to non-explanatory syndromic diagnoses because they bring both epistemic and therapeutic benefits to patients and their providers. They therefore advocate a methodology of causal explanatory pluralism in the diagnosis of MUPS.

This short subsection concludes with a paper that emphasizes the uniqueness of individual cases, stressing the limitations of aggregate-based reasoning and calling for a much broader range of factors to be incorporated into clinical thinking and decision making. It is fitting that the subsection concludes with a paper by an author who raised some of the earliest alarms about the use of statistical aggregates to inform conclusions about the treatment of specific patients, in the first volume of the journal, 20 years ago [25]. Sandra Tanenbaum [56] reviews the history and prominent defences of the statistical aggregate in medicine, concluding that its principle masters are not only epistemic but also political. Thus, if the 'knowledge of particulars' needed to help cross the gap between aggregates and individuals is to be seen as epistemically legitimate, it must be politically legitimated through educational and quality assurance initiatives that recognize its importance. This discussion sets the scene for a series of essays exploring the human and social aspects of care.

\section{Experience, caring, community and humanity: philosophy at the bedside}

At a time when authors writing under the label of 'real' EBM endorse the criticisms made in the JECP over so many years [71], it is particularly appropriate to look in detail at the factors that earlier exponents either overlooked or treated as aspects of the clinical encounter to be 'integrated' into EBM at a later stage. As the exponents of 'real' EBM clearly agree, the time for an intellectually serious effort to integrate these human, social and experiential factors into a more comprehensive account of clinical practice is very much upon us. Many clinicians may ask, aside from ethics, what business does philosophy have at the bedside? Even if many practitioners are not sensitized to the numerous conceptual and epistemological issues that arise in clinical care, these issues are no less pressing. Many of the papers in this volume speak to the need to reconsider and renew the conceptual structure of medicine.

Henrik Vogt and his colleagues support the development of an organismic, whole-oriented systems medicine for its potential to help reinstate the person in medical care [57]. At the same time, they draw insightful attention to constraints on its potential within primary care to close the gap between scientific and humanistic constructions of patients, and their health problems, in all their complexity. The authors note that within the field of systems medicine, the most humanistic theory focuses on patients as integrative sites and processes of activity at all levels and scales. However, they question whether any philosophy of systems medicine can yet yield a fully personalizing science able to feed into humanistic medicine. Sceptical that systems medicine can become a complete foundation for clinical understanding and practice by accommodating humanistic concepts of experience, meaning and value, they argue for the need to complement systems medicine with the use of other methods.

Victor Cellarius and Ross Upshur argue that the current demographic transition, typified in high income settings by an ageing population and more concurrent chronic illnesses, necessitates a reconsideration of medical care in the late life course [58]. It has taken decades for palliative care to be accepted as an integrated component of modern medicine, but the sharp demarcation of what sort of patient qualifies for palliation has been blurred. Cellarius and Upshur articulate the concept of teleological care, that is, medicine that is focused on reasoning about telos (i.e. end) in three senses: (1) the end of life as a temporal limit; (2) the end of life as the individual's purpose and meaning; and (3) the end of life as the meaning of life as a whole. Integrating these strands would result in a mode of emphasis of care away from specialization and embracing a robust generalism.

Stephen Buetow's paper shifts the focus again, emphasizing the relational aspects of care and the moral agency of the patient as a person [59]. He makes the important claim that most patients need to, and can, care about clinicians. Such caring supports the wellbeing and personhood of the clinician on whose care the patient depends. It contributes thereby to a repersonalization of health care amid a crisis of loss of compassion, reflected not only in the ways that clinicians' actions can dehumanize patients but also in rising complaints by patients. Against this backdrop, Buetow suggests how patients can care about a clinician even when the clinician appears uncaring. Drawing on the philosophy and psychology of Hans Vaihinger's 'as if' theory, Buetow's approach requires the patient to imagine and act as if the apparently uncaring clinician is caring - so long as the uncaring is minor and uncertain to the patient. Use of the approach may require clinicians to remind patients in such circumstances to give them the benefit of the doubt. Testing this approach against his experience as a patient, Buetow finds it both 'relationship-protecting' and useful in rendering uncertainty (often treated as a negative in health care) productive.

Shawn Whatley argues that clinical medicine must work with scholars in the humanities to develop its own 'sui generis' philosophy of medicine [60]. Whatley notes that medical education is predominated by a reductive form of physicalism, and despite efforts to bring a biopsychosocial frame to understanding health and disease, medical students by and large accept a metaphysic of physicalism. For Whatley, remedying this is a central challenge for both the philosophy of medicine and medical education.

Ignaas Devisch and Stijn Vanheule draw on the work of the French philosopher Jean-Luc Nancy in their discussion of autonomy and paternalism in clinical medicine [61]. Nancy argues that there is strictly no such thing as autonomy, because the individual develops a sense of identity or self heteronomously, in the context of a broader community on the basis of input from external sources, including other individuals. The authors use this as a basis 
from which to argue that developments in medical technology, with its inherently 'intruding' nature, make it urgent that we rethink the ideas of autonomy and selfhood and their importance in medicine.

From experience of serious illness as a patient - his own experience and that recounted by Havi Carel in her book, Illness [72] former Health Service manager and philosopher Derek Mitchell further suggests what is needed to rehumanize modern health care [62]. Looking beyond systems and procedures, beyond biological and normative conceptions of illness, Mitchell focuses on how real improvements in patient care depend, at the bedside, on the virtuous practitioner. In action, this moral agent is responsive both situationally to the complexity of the health setting and relationally to the unique lived experience of the patient; the patient as a person whose being is disrupted by illness and exposed to the practitioner, for example, through narrative. Mitchell argues for improving the stories that patients tell rather than the measures against which practitioners are judged.

Referring to the definition of mental disorder in the fifth Diagnostic and Statistical Manual of Mental Disorders (DSM-5), Stijn Vanheule and Ignaas Devisch [63] note that mental disorders are usually associated with significant distress. However, the handbook is vague with respect to whether distress is crucial to the diagnosis of mental disorders, and a conceptual framework on the precise nature of distress is lacking. As a result, it remains vague how the term 'distress' is to be taken into account in actual diagnostic situations: DSM-5 provides no operational framework for diagnosing distress. Using the work of Georges Canguilhem on abnormality and pathology, and Paul Ricoeur's philosophical work on mental suffering, the authors aim to provide a structure for conceptualizing and evaluating distress. According to Ricoeur's phenomenological model, distress is not a quantity that can be measured, but a characteristic that should be studied qualitatively in interpersonal and narrative contexts: diagnosticians should describe and document how individuals experience subjective distress. On a practical level, this means that clinicians' ideas about patients' distress should be embedded in case formulations. A detailed evaluation of an individual's pathos experience should be made before conclusions are drawn with regard to diagnosis.

This issue obviously has implications for understanding distress that go beyond the important issue of its role in DSM-5, and the paper is a fine illustration of the unavoidable nature of philosophical reflection if we are to find an adequate basis for practice.

\section{Debates}

As we noted, a great virtue of philosophy is its ability to cut through superficial appearances of consensus and to remind us that certain problems of a pressing and fundamental nature have not been resolved. Even when particular ideas and approaches have become dominant, critical reflection can enable us to see that they are by no means necessary, and such thinking can sometimes be an essential prerequisite of progress in a given area [5]. One of the great achievements of the JECP and its thematic editions has been in provoking debate about fundamentals - something we celebrate by unapologetically continuing the fundamental debates about causal ontology and about foundationalism in medicine that were raised and not resolved in previous issues.
In a previous Philosophy Thematic issue, Roger Kerry and colleagues [29] argued that EBM should adopt a dispositionalist metaphysics of causation. In this issue, Anders Strand and VeliPekka Parkkinen [64] champion an alternative, difference-making account of causality, which had been rejected by Kerry et al. Strand and Parkkinen contend that discussions of causality in medicine should focus on epistemological, rather than ontological, issues, and they argue that a difference-making approach to causality better supports inferences from research evidence to clinical decisions. In a reply to this paper, Kerry et al. [65] argue that their dispositionalist approach does ground clinical reasoning and, further, they claim that there is a good reason for philosophy of medicine to address ontological as well as epistemological questions about causation.

Ross Upshur [66] responds to Miles Little's essay from the previous thematic issue [73]. Little sought to defend what he terms a 'modest foundationalism'. While sympathetic to Little's arguments, Upshur argues that the notion of foundations, even modest, is incoherent. It is unclear why medicine needs a singular base or centre and the motivation for seeking one is also not well articulated. Upshur argues for a pragmatic fallibilism as the orienting epistemology for medicine.

\section{Conference reports}

We include two conference reports providing an overview of some of the active topics in the philosophy of medicine. Maël Lemoine and colleagues [67] report on the first biennial meeting of the International Advanced Seminar in the Philosophy of Medicine (IASPM). The IASPM was initiated by five research centres: the Centre for Humanities and Health at King's College (London, UK), the Institut für Geschichte, Theorie und Ethik der Medizin at Johannes Gutenberg (Mainz, Germany), the European School of Molecular Medicine (Milan, Italy), the IHPST at PanthéonSorbonne (Paris, France) and the Department of History and Philosophy of Science at Pittsburgh (USA). The mission of the meeting was to contribute to the consolidation of the philosophy of medicine as a field by bringing together junior researchers and senior academics for a 3-day conference exploring current and future directions in the field.

Emma Bullock and Elselijn Kingma [68] report on the fifth in a series of 1-day workshops organized by the Centre for Humanities and Health at King's College London. The goal of the workshops is to provide a new model for high-quality, open interdisciplinary engagement between medical professionals and philosophers, and under the broad heading of 'Medical Knowledge, Medical Duties', the invited audience of professionals and academics debated current controversies concerning public and private goods, expertise and obligation, EBM and person-centered medicine, particularism and judgement.

\section{Book review}

We conclude with a review of Alex Broadbent's new monograph Philosophy of Epidemiology from Jonathan Fuller [69]. Broadbent boldly opens up the philosophy of epidemiology as a new subdiscipline in the philosophy of medicine and the philosophy of science. His book carefully and articulately addresses important, often unchartered problems that are relevant to philosophers and 
epidemiologists alike, including the readership of the JECP, and particularly readers of the Philosophy Thematic editions.

\section{Conclusion}

The political and social evolution of health care has been rapid and dramatic, especially over the last 20 years. The growth of the philosophy of medicine and its expansion into new areas of inquiry has kept up. Through the first five philosophy of medicine thematics of the journal, including the present edition, progress has been made in clarifying the ethical, epistemic and methodological health care problems of our time, scrutinizing dominant beliefs and practices, and rigorously defending alternative views. This is philosophy - but philosophy applied to the real concerns of health care providers and patients, philosophy concerned with evaluating clinical practice. We hope that future issues continue to foster discussion and collaboration between philosophers, clinicians and clinical researchers, and we look forward to the next 20 years of growth, progress and scholarship.

\section{References}

1. Loughlin, M., Upshur, R., Goldenberg, M. J., Bluhm, R. \& Borgerson, K. (2010) Philosophy, ethics, medicine and health care: the urgent need for critical practice. Journal of Evaluation in Clinical Practice, 16 (2), 249-259.

2. Seedhouse, D. F. (1999) Camouflage is no defence - a response to Kottow. Journal of Medical Ethics, 25, 344-348.

3. Loughlin, M. (2002) Ethics, Management and Mythology: Rational Decision Making for Health Service Professionals. Oxon: Radcliffe Medical Press.

4. Loughlin, M. (2004) Camouflage is still no defence: another plea for a straight answer to the question 'what is bioethics?' Journal of Evaluation in Clinical Practice, 10 (1), 75-83.

5. Loughlin, M., Bluhm, R., Buetow, S., Goldenberg, M. J., Upshur, R., Borgerson, K. \& Entwistle, V. (2011) Virtue, progress and practice. Journal of Evaluation in Clinical Practice, 17 (5), 839-846.

6. Loughlin, M., Bluhm, R., Buetow, S., Goldenberg, M., Upshur, R., Borgerson, K., Entwistle, V. \& Kingma, E. (2012) Reason and value: making reasoning fit for practice. Journal of Evaluation in Clinical Practice, 18 (5), 929-939.

7. Loughlin, M., Bluhm, R., Stoyanov, D., Buetow, S., Upshur, R., Borgerson, K., Goldenberg, M. J. \& Kingma, E. (2013) Explanation, understanding, objectivity and experience. Journal of Evaluation in Clinical Practice, 19 (3), 415-421.

8. Secretaries of State for Health, Wales, Northern Ireland and Scotland (1989) Working for patients. HMSO, London.

9. PA Consulting Group (1989) How to Take Part in the Quality Revolution: A Management Guide. London: PA Consulting Group.

10. Al-Assaf, A. F. \& Schmele, J. A. (eds) (1993) The Textbook of Total Quality in Healthcare. Delray Beach, FL: St Lucie Press.

11. Joss, R. \& Kogan, M. (1995) Advancing Quality: Total Quality Management in the National Health Service. Buckingham: Open University Press.

12. McIntyre, N. (1995) Evaluation in clinical practice: problems, precedents and principles. Journal of Evaluation in Clinical Practice, 1 (1), 5-13.

13. Miles, A., Grey, J. \& Polychronis, A. (1995) Purchasing quality in clinical practice: what on earth do we mean? Journal of Evaluation in Clinical Practice, 1 (2), 87-95.

14. Loughlin, M. (1995) Brief encounter: a dialogue between a philosopher and an NHS manager on the subject of 'quality'. Journal of Evaluation in Clinical Practice, 1 (2), 81-85.
15. Loughlin, M. (1996) The language of quality. Journal of Evaluation in Clinical Practice, 2 (2), 87-95.

16. Mill, J. S. (1991) On Liberty (eds J. Gray \& G. W. Smith) London: Routledge.

17. Shaw, G. B. (1948) Man and Superman. London: Penguin Books.

18. Wall, A. (1993) Values and the NHS. Institute of Health Services Management, London.

19. IHSM (1993) Future Health Care Options, Final Report. Institute of Health Services Management, London.

20. Henry, C. (ed.) (1995) Professional Ethics and Organisational Change in Education and Health Care. London: Edward Arnold.

21. Tonelli, M. (2006) Integrating evidence into clinical practice. Journal of Evaluation in Clinical Practice, 12 (3), 248-256.

22. Thornton, T. (2011) Radical, liberal values-based practice. Journal of Evaluation in Clinical Practice, 17 (5), 988-991.

23. Duncan, P. (2010) Health, heath care and the problem of intrinsic value. Journal of Evaluation in Clinical Practice, 16 (2), 318323.

24. Hamilton, R. (2010) The concept of health: beyond normativism and naturalism. Journal of Evaluation in Clinical Practice, 16 (2), 323329.

25. Tanenbaum, S. (1995) Getting there from here: evidentiary quandaries of the US outcomes movement. Journal of Evaluation in Clinical Practice, 1 (2), 97-104.

26. Polychronis, A., Miles, A. \& Bentley, P. (1996) The protagonists of 'evidence-based medicine': arrogant, seductive and controversial. Journal of Evaluation in Clinical Practice, 2 (1), 9-12.

27. Bluhm, R. (2013) Physiological mechanisms and epidemiological research. Journal of Evaluation in Clinical Practice, 19 (3), 422-426.

28. Andersen, H. (2012) Mechanisms: what are they evidence for in evidence-based medicine? Journal of Evaluation in Clinical Practice, 18 (5), 992-999.

29. Kerry, R., Eriksen, T. E., Lie, S. A. N., Mumford, S. D. \& Anjum, R. (2012) Causation and evidence-based practice: an ontological review. Journal of Evaluation in Clinical Practice, 18 (5), 1006-1012.

30. Miles, A. \& Loughlin, M. (2006) Editorial introduction and commentary 'continuing the evidence-based health care debate: the progress and the price of EBM'. Journal of Evaluation in Clinical Practice, 12 (4), 385-398.

31. Buetow, S., Upshur, R., Miles, A. \& Loughlin, M. (2006) Taking stock of evidence-based medicine. Journal of Evaluation in Clinical Practice, 12 (4), 399-404.

32. Upshur, R., Buetow, S., Loughlin, M. \& Miles, A. (2006) Can academic and clinical journals be in financial and ideological conflict of interest situations? The case EBM incorporated. Journal of Evaluation in Clinical Practice, 12 (4), 405-409.

33. Henry, S. (2010) Polanyi's tacit knowing and the relevance of epistemology to clinical medicine. Journal of Evaluation in Clinical Practice, 16 (2), 292-297.

34. Cartwright, N. \& Munro, E. (2010) The limitations of randomized controlled trials in predicting effectiveness. Journal of Evaluation in Clinical Practice, 16 (2), 260-266.

35. Thompson, R. P. (2010) Causality, mathematical models and statistical association: dismantling evidence-based medicine. Journal of Evaluation in Clinical Practice, 16 (2), 260-275.

36. Goldenberg, M. J. (2010) From Popperian science to normal science. Journal of Evaluation in Clinical Practice, 16 (2), 306-310.

37. Worrall, J. (2010) Evidence: philosophy of science meets medicine. Journal of Evaluation in Clinical Practice, 16 (2), 356-362.

38. Upshur, R. (2013) A short note on probability in clinical medicine. Journal of Evaluation in Clinical Practice, 19 (3), 463-466.

39. Braude, H. (2012) Conciliating cognition and consciousness: the perceptual foundations of clinical reasoning. Journal of Evaluation in Clinical Practice, 18 (5), 945-950. 
40. Miles, A., Loughlin, M. \& Polychronis, A. (2008) Editorial introduction and commentary: 'evidence-based health care, clinical knowledge and the rise of personalised medicine'. Journal of Evaluation in Clinical Practice, 14 (5), 621-649.

41. Marcum, J. (2012) An integrated model of clinical reasoning: dual process theory of cognition and metacognition. Journal of Evaluation in Clinical Practice, 18 (5), 954-961.

42. Upshur, R. \& Gupta, M. (2012) Critical thinking in clinical practice: what is it? Journal of Evaluation in Clinical Practice, 18 (5), 938-944.

43. Macnaughton, J. (2011) Medical humanities' challenge to medicine. Journal of Evaluation in Clinical Practice, 17 (5), 927-932.

44. Kirkengen, A. L. \& Thornquist, E. (2012) The lived body as a medical topic: an argument for an ethically informed epistemology. Journal of Evaluation in Clinical Practice, 18 (5), 1095-1101.

45. Gergel, T. (2012) Medicine and the individual - is phenomenology the answer? Journal of Evaluation in Clinical Practice, 18 (5), 11021109.

46. Miles, A., Bentley, P., Polychronis, A. \& Grey, J. E. (1997) The limits of evidence-based medicine. Journal of Evaluation in Clinical Practice, 3 (1), 83-86.

47. Miles, A., Bentley, P., Polychronis, A., Grey, J. E. \& Price, N. (1999) Advancing the evidence-based healthcare debate. Journal of Evaluation in Clinical Practice, 5 (1), 97-101.

48. Miles, A., Charlton, B. G., Bentley, P., Polychronis, A., Grey, J. E. \& Price, N. (2000) New perspectives in the evidence-based healthcare debate. Journal of Evaluation in Clinical Practice, 6 (1), 77-84.

49. Miles, A., Bentley, P., Polychronis, A., Grey, J. E. \& Melchiorri, C. (2001) Recent developments in the evidence-based healthcare debate. Journal of Evaluation in Clinical Practice, 7 (1), 85-89.

50. Miles, A., Grey, J. E., Polychronis, A., Price, N. \& Melchiorri, C. (2003) Current thinking in the evidence-based healthcare debate. Journal of Evaluation in Clinical Practice, 9, 95-109.

51. Miles, A., Loughlin, M. \& Polychronis, A. (2007) Medicine and evidence: knowledge and action in clinical practice. Journal of Evaluation in Clinical Practice, 13 (4), 481-503.

52. Every-Palmer, S. \& Howick, J. (2014) How evidence-based medicine is failing due to biased trials and selective publication. Journal of Evaluation in Clinical Practice, 20, 6.

53. Mebius, A. (2014) Corroborating evidence-based medicine. Journal of Evaluation in Clinical Practice, 20, 6 doi:10.1111/jep12129.

54. Chin-Yee, B. (2014) Under-determination in evidence-based medicine. Journal of Evaluation in Clinical Practice, 20 (6), 921-927.

55. Cournoyea, M. \& Kennedy, A. (2014) Causal explanatory pluralism and medically unexplained physical symptoms. Journal of Evaluation in Clinical Practice, 20, 6 doi:10.1111/jep12238.

56. Tanenbaum, S. (2014) Particularism in health care: challenging the authority of the aggregate. Journal of Evaluation in Clinical Practice, 20 (6), 934-941.

57. Vogt, H., Ulvestad, E., Eriksen, T. E. \& Getz, L. (2014) Getting personal: can systems medicine integrate scientific and humanistic conceptions of the patient? Journal of Evaluation in Clinical Practice, 20 (6), 942-952.

58. Cellarius, V. \& Upshur, R. (2014) Teleological care and the final years of life. Journal of Evaluation in Clinical Practice, 20 (6), 953-956

59. Buetow, S. (2014) Caring about the clinician who seems uncaring: the 'as-if' approach. Journal of Evaluation in Clinical Practice, 20 (6), 957-960

60. Whatley, S. (2014) Borrowed philosophy: bedside physicalism and the need for a sui generis metaphysic of medicine. Journal of Evaluation in Clinical Practice, 20 (6), 961-964.

61. Devisch, I. \& Vanheule, S. (2014) Singularity and medicine: is there a place for heteronomy in medical ethics? Journal of Evaluation in Clinical Practice, 20 (6), 965-969.

62. Mitchell, D. (2014) Philosophy at the bedside - phenomenology, complexity and virtue in the care of patients. Journal of Evaluation in Clinical Practice, 20 (6), 970-974.

63. Vanheule, S. \& Devisch, I. (2014) Mental suffering and the DSM-5: a critical review. Journal of Evaluation in Clinical Practice, 20 (6), 975-980.

64. Strand, A. \& Parkkinen, V.-P. (2014) Causal knowledge in evidencebased medicine - reply to Kerry et al. Journal of Evaluation in Clinical Practice, 20 (6), 981-984.

65. Kerry, R., Eriksen, T. E., Lie, S. A. N., Mumford, S. D. \& Anjum, R. L. (2014) Causation in evidence-based medicine: in reply to Strand and Parkkinen. Journal of Evaluation in Clinical Practice, 20 (6), 985-987.

66. Upshur, R. (2014) Conventions or foundations? A response to Miles Little's ex nihilo nihil fit. Journal of Evaluation in Clinical Practice, 20 (6), 988-990.

67. Lemoine, M., Darrason, M. \& Richard, H. (2014) Where is philosophy of medicine heading to? A report of the International Advanced Seminar in the Philosophy of Medicine (IASPM). Journal of Evaluation in Clinical Practice, 20 (6), 991-993.

68. Bullock, E. \& Kingma, E. (2014) Conference report: interdisciplinary workshop in the philosophy of medicine: medical knowledge, medical duties. Journal of Evaluation in Clinical Practice, 20 (6), 994-1001.

69. Fuller, J. (2014) Essay review of Alex Broadbent's book 'philosophy of epidemiology'. Journal of Evaluation in Clinical Practice, 20 (6), 1002-1004

70. Sehon, S. R. \& Stanley, D. E. (2003) A philosophical analysis of the evidence-based medicine debate. BMC Health Services Research, 3 (1), 14.

71. Greenhalgh, T., Howick, J. \& Maskery, N. (2014) Evidence based medicine: a movement in crisis? BMJ (Clinical Research Ed.), 348, g3725.

72. Carel, H. (2008) Illness. Durham: Acumen.

73. Little, M. (2013) Ex nihilo nihil fit? Medicine rests on solid foundations. Journal of Evaluation in Clinical Practice, 19, 467-470. 